\title{
The plastic collapse of framed structures clad with corrugated steel sheeting
}

\author{
J. M. DAVIES
}

\section{Dr Davies}

One important question raised in the Paper and not satisfactorily answered concerned the ductility of sheeting panels. Since writing the Paper more panel tests have been conducted and the behaviour up to final failure has been more closely observed.

64. Figure 20 shows a typical case of direct shear transfer, with the sheeting continuous over an intermediate purlin. The observed failure load of $30 \mathrm{kN}$ was very close to the predicted value of $29 \cdot 2 \mathrm{kN}$. This time the length of the yield plateau was measured. At the failure load, the sheeting panel resisted constant load as the deflexion increased from $24 \mathrm{~mm}$ to approximately $70 \mathrm{~mm}-$ a yield plateau about $45 \mathrm{~mm}$ long.

65. Figure 21 shows the more flexible case of indirect shear transfer. Again the correspondence between calculated and observed failure loads is excellent. This time the length of the yield plateau at the failure load was about $75 \mathrm{~mm}$.

66. Figure 22 shows details of a typical failure of the type appropriate to Figs 20 and 21. In this case it is failure at the fasteners between the sheeting and the shear connector. The considerable ductility possessed by sheeting panels is only achieved at the expense of permanent damage to the sheeting of a serious nature. There is a considerable tear in the sheeting at the fasteners.

67. In extreme cases such as this the damage may be so great that, on removing the shear load and then reloading the panel, the fastener parts completely from the sheeting and the same load may not be achieved on reloading.

68. For this reason, although plastic designs of stressed skin structures are possible, they must not make excessive demands on the ductility of the sheeting panels. Yield of the sheeting at the fasteners must be delayed until well beyond the working range. To ensure this an elastic analysis of the clad structure is essential.

\section{Professor J. Heyman, University of Cambridge}

The Paper is one in the valuable series of studies of plastic collapse of sheeted low-rise buildings. It is becoming clear that, assuming certain safeguards, it is now possible to predict with some accuracy the collapse loads of composite structures of this type, and thus their design and construction can be undertaken with some confidence.

70. The safeguards referred to are concerned in the main with ductility. The frame material itself must, of course, be ductile. In addition, the sheeting material must be capable of accepting large deformations before the onset of fracture or instability. Most important, the connexion details must also be of adequate strength and ductility. There was, of course, an object lesson in this in the premature failure of the seam fasteners reported by the Author in his test on the rectangular portalframe building at Barton ( $(42)$.

71. However, the Author's conclusion that the behaviour of such buildings up to collapse can now be predicted adequately is certainly justified. This conclusion for low-rise buildings is in contrast with that for high-rise buildings, where the first steps are only just being taken. Oppenheim ${ }^{12}$ has discussed the cladding of tall buildings,

Paper published: Proc. Instn Civ. Engrs, Part 2, 1973, 55, Mar., 23-42. 
DISCUSSION

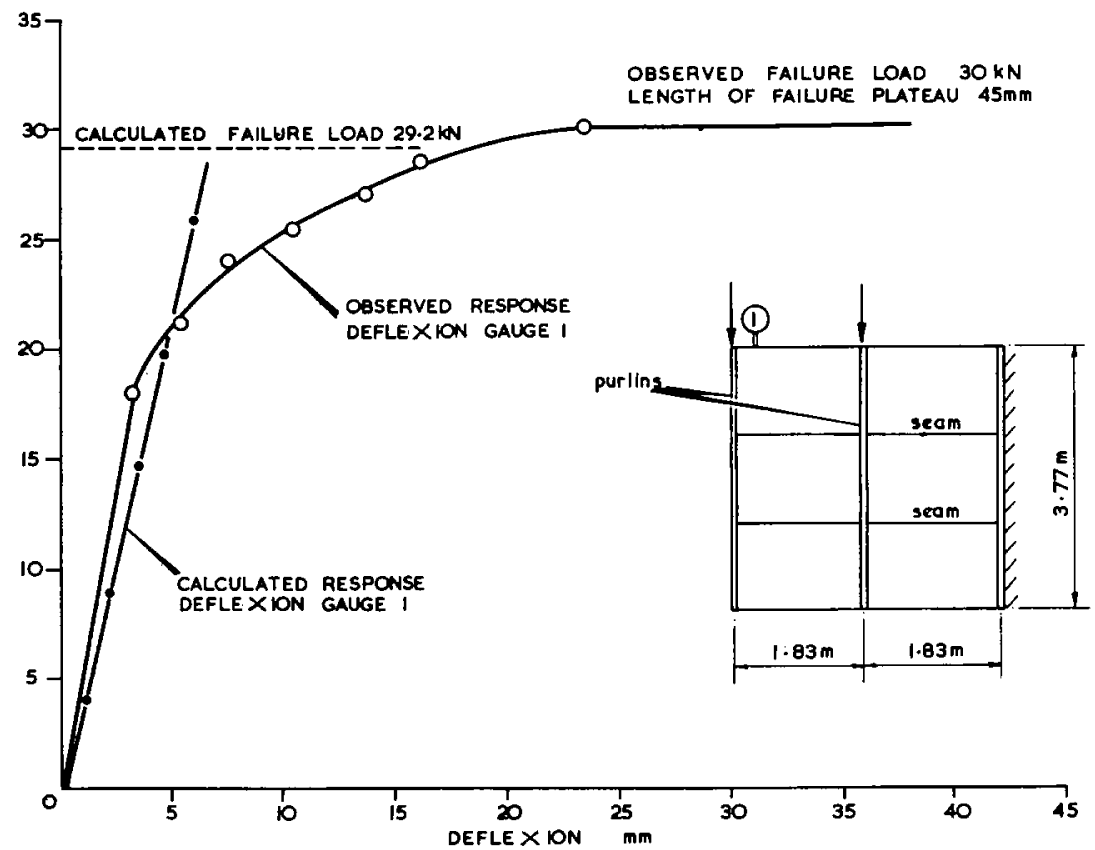

Fig. 20. Panel with direct shear transfer

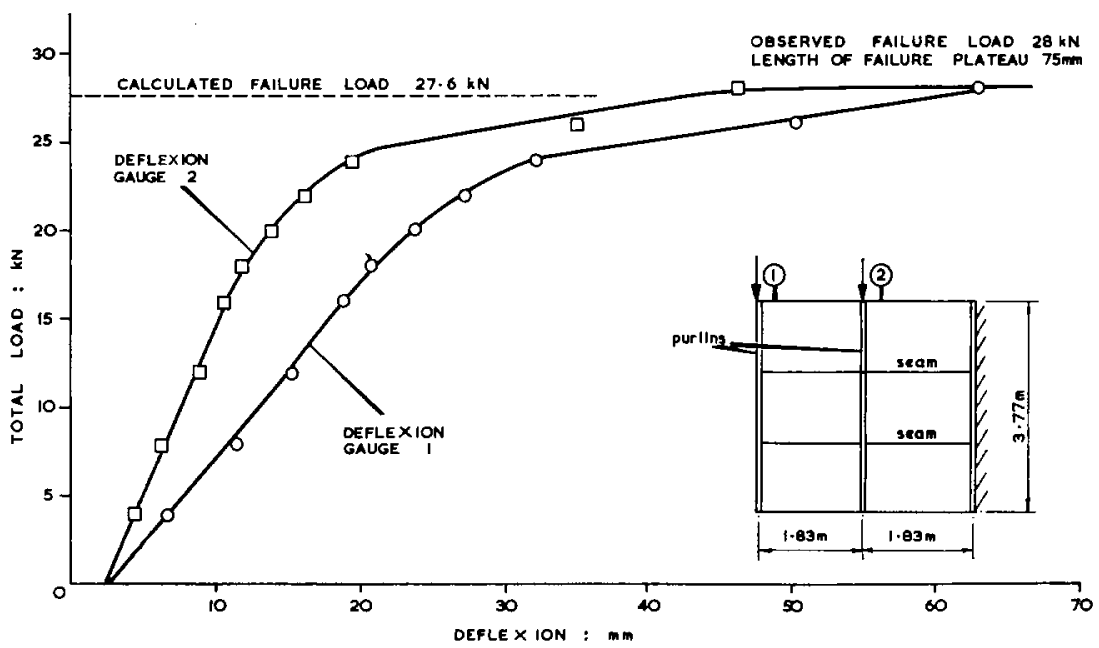

Fig. 21. Panel with indirect shear transfer

720

Downloaded by [] on [26/04/23]. Copyright (C) ICE Publishing, all rights reserved. 


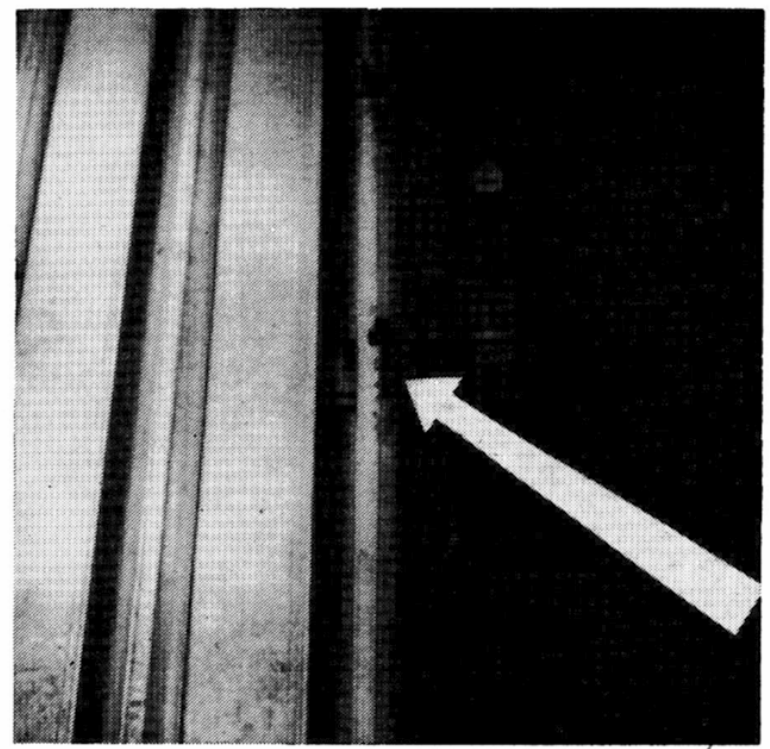

Fig. 22

and distinguishes three possible stages in tackling the problem of allowing for the interaction of sheeting and frames.

72. The first and simplest stage is to design the bare frame from strength considerations (using an elastic or a plastic method) and then to design cladding to satisfy any deflexion requirements that may be imposed. This is, of course, only a small move away from the conventional way of looking at steelwork design. A second and more sophisticated stage in the development of a composite design process is to require the bare frame to carry gravity loads only, and to require the cladding to carry lateral loads. Finally, the whole structure can be regarded as composite from the start of the design process, and a method developed which will generate relative proportions of frame and cladding.

73. This third stage may be remote for the tall building, but Dr Davies is almost there with his work on the low-rise structure. One further step is perhaps needed, namely an allowance (perhaps approximate) for the effect of deflexions. Although analysis gives deflexions, the Author makes the usual assumption that these are small compared with overall dimensions of the structure. Changes in geometry are therefore neglected, but they can be important in pitched-roof frames.

74. In this connexion Fig. 1 and the analysis in $\$ \S 9$ and 10 are misleading, although the final result is correct on a small deflexion basis. In Fig. 1 the eaves lines and the ridge line of the collapsing shed are shown curved, with each frame having a slightly different elastic-plastic deformation from those of its neighbours. In reality, however, the analysis is rigid-plastic; the hinge rotations $\phi$ in Fig. 2 are in fact assumed to be the same for each of the five collapsing frames.

75. Thus the assumed deformation pattern really corresponds to that shown in Fig. 23 in which the five central frames are compelled to move together by the rigid sheeting connecting them; deformation is possible because of the limiting shear (of $20.4 \mathrm{kN}$ ) being reached in the four sheets in the end bays. Dr Davies computes a restraining force of $2 \times 20.4 \mathrm{kN}$ acting in the plane of each half rafter, and then divides 


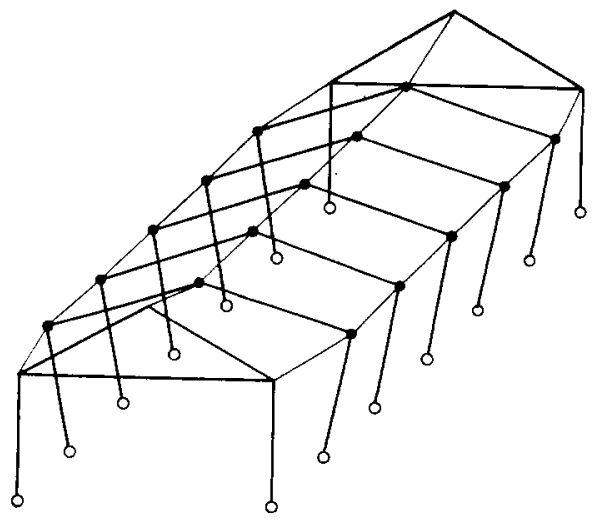

Fig. 23

this equally between the five internal frames to give an inclined force of $8.16 \mathrm{kN}$, or $8.16 \times \cos 30^{\circ}=7.07 \mathrm{kN}$ horizontally. These fictitious forces are shown in Fig. 2, and they lead to the collapse equation given in $\S 10$.

76. Although the result of this equation is correct, the second term should really appear on the other side, in the form

(work done by loads) $=$ (work done in hinges) + (work done in sheeting)

The work done in the sheeting is in this case merely the limiting shear times the relative displacement, i.e. $4 \times 20.4 \times 1.41 \phi \times \cos 30^{\circ}$, i.e. five times the value shown by $\mathrm{Dr}$ Davies. The loading and hinge terms must, of course, also be multiplied by 5 to represent the contributions of the five frames.

77. The matter seems trivial, because the terms in one equation are merely five times those of the other, but it is unnecessary to introduce fictitious horizontal forces, and it may in fact be misleading to do so. Thus Dr Davies assumes an equal distribution between the frames, but the plastic collapse analysis actually gives no information about the internal forces in the sheeting. These will in practice not be equally distributed, but, when elastic deformations are taken into account, they will be higher on frames 1 and 5 than on frames 2,3 and 4 .

78. No harm is done if the values of the internal forces are not required for design of local details. However, if such information is needed plastic methods will only give bounds to the values, and closer estimates must be made in some other way.

\section{Professor E. R. Bryan, University of Salford}

I should like to re-emphasize the design philosophy which has been propounded up to date, i.e. that in using sheeting in this way one should design the bare frame by itself to carry all the design loads without collapse and with a suggested load factor of 1-15. In the complete sheeted building the suggested load factor against collapse should be 1.75 for normal buildings. If these measures are adopted there should never be any risk of the collapse of the building in the erection stage or at any other stage in the life of the building. This measure disposes to some extent of the argument that the building might be unsafe if an important cladding panel were removed.

80. Would Dr Davies enlarge on his conclusions in $\$ 59$ because an analysis by itself cannot provide a constraint? I think he means that there must be a conscious design measure, but what, in practice, does this measure amount to?

81. The most important conclusion drawn from this systematic analysis of the 
previous tests on buildings - bearing in mind that they were carried out both on conventional type buildings and on a building designed on stressed skin principles-is that whether a structure is designed elastically or plastically, or whether sheeting is taken into account in design or not, it is likely that first yield will occur in the sheeting panels, and that this may occur at the working loads. Engineers do not generally appreciate this fact.

82. Having hinted at the prospect of plastic design of sheeted buildings, I should be interested to hear the Author's opinions as to what obstacles need to be overcome before this method of design can be confidently adopted. Will it be a device just for obtaining suitable member sizes, which would then need to be checked by elastic methods of stressed skin design at working loads, or is it possible to go straight in with confidence and design the clad structure using plastic methods? Obviously the latter concept is preferable, because the method is logical and easy to apply. Moreover, if one does this Horne's work on column and rafter stability can be incorporated, and it would tie up the whole of design of this type of steel structure very conveniently.

83. A load factor of 1.75 for a clad structure has been mentioned. To what extent has this figure been chosen arbitrarily? Can Dr Davies substantiate it further?

\section{Professor K. I. Majid, University of Aston}

In 1960-1963 a team of three people were engaged at Manchester University in the application of computers to the analysis of general structures. The leader was $\mathrm{Mr}$ A. Jennings, now Reader at Belfast, and Dr Davies and I were research students working with him to develop various programs. We developed the first program to analyse general frames elasto-plastically up to failure. ${ }^{13}$ It is this program that Dr Davies is describing to analyse three-dimensional structures. The application of the program in this manner is indeed admirable.

85. While Dr Davies was extending the program to include strain hardening and shake-down effects, I studied the three-dimensional approach to complete structures. I was associated with the tests in the Paper, described in $\S \S 26,33-35$, and Figs 1, 6 and 10. I also did the first rigid plastic analysis of the shed. ${ }^{3.14}$

86. Of the elastic-plastic work described by Dr Davies it can be said that it records progress in three significant fields.

87. First, it moves away from two-dimensional frame analysis to a more realistic three-dimensional approach.

88. Second, the Author's work moves away from the rigid plastic method to a more accurate elasto-plastic method. After the initial enthusiasm about the rigid plastic theory in the 1950 s, it became clear that this would never be able to analyse dams, domes, towers, radio telescopes, bridges and other structures. The mechanism approach, which is the most essential aspect of the plastic theory, does not apply to any concrete structure or building. Nor does it apply to tall steel buildings because of instability and large defiexion effects. This leaves only a few simple frames, and Dr Davies provides ample evidence to show that the rigid plastic method is but an oversimplification of the problem.

89. Third, Dr Davies makes use of an existing two-dimensional analysis program to solve a three-dimensional problem. The effort, while idealistic, makes an existing two-dimensional program more versatile. The work involved is reduced to mere data punching for the structure.

90. Nevertheless, there is more to a true three-dimensional elasto-plastic analysis of complete structures than is described in the Paper. Dr Davies expresses the stiffness of the cladding by a spring of a single constant property which was obtained experimentally and which therefore has only an empirical value. No doubt Dr Davies would agree that there is no such single constant that represents the panel flexibility. Indeed, for the case of plane cladding there is a matrix 


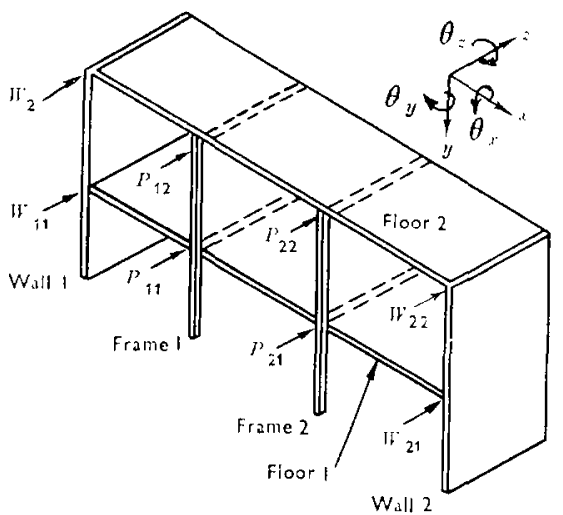

Fig. 24. Numbering of wall and frame junctions

$$
\left[\begin{array}{ll}
\mathbf{K}_{\mathrm{uu}} & \mathbf{K}_{\mathrm{uv}} \\
\mathbf{K}_{\mathrm{vu}} & \mathbf{K}_{\mathrm{vv}}
\end{array}\right]=\left[\begin{array}{cccccc}
c & 0 & -d & -c & 0 & -d \\
0 & q & 0 & 0 & -q & 0 \\
-d & 0 & b & d & 0 & a \\
-c & 0 & d & c & 0 & d \\
0 & -q & 0 & 0 & q & 0 \\
-d & 0 & a & d & 0 & b
\end{array}\right]
$$

where $u$ and $v$ are two adjacent frames connected by the cladding, $a=2 E I \phi(1-\beta) / 1$, $b=2 E I \phi(2+\beta) / L, c=12 E I \phi / L^{3}, d=6 E I \phi / L^{2}, q=G B t^{3} / 3 L, \quad \phi=1 /(1+2 \beta), \beta=7 \cdot 2 E I /$ $L^{2} A G, t$ is the thickness, $A$ is the area and $I$ is the second moment of area of the cladding slab considering it as a deep beam. Here the cladding is considered to be part of a grillage system with degrees of freedom in the $z, \theta_{x}$ and $\theta_{y}$ directions as shown in Fig. 24. In the case of plane sheeting, the in-plane bending stiffness of the cladding in the $\theta_{y}$ direction is too great to be neglected. Neglecting the stiffness of the cladding in the $\theta_{x}$ and $\theta_{y}$ directions, the matrix in equation (1) reduces to

$$
\left[\begin{array}{cc}
c & -c \\
-c & c
\end{array}\right]
$$

It is the experimental value of $c$ that Dr Davies used to represent the stiffness of the sheeting.

91. Figure 24 shows a three-dimensional building structure consisting of a number of parallel frames of any shape, toget her with slabs and shear walls. The structure is subject to wind loads acting at the junctions of the slabs with the shear walls and frames. Considering the equilibrium and the compatibility conditions at these junctions it is possible to establish the manner in which the applied loads $\mathbf{P}$ are shared by the frames and the grillage of slabs and walls. Thus

$$
\mathbf{P}=\mathbf{F}+\mathbf{G}
$$

where $\mathbf{F}$ is a vector representing that portion of $\mathbf{P}$ which is transmitted to the frame, while vector $\mathbf{G}$ is transmitted to the slabs and the shear walls. Each element $p$ of a vector $\mathbf{P}$ can be written as

or

$$
p=f+g
$$

$$
1=\frac{f}{p}+\frac{g}{p}
$$




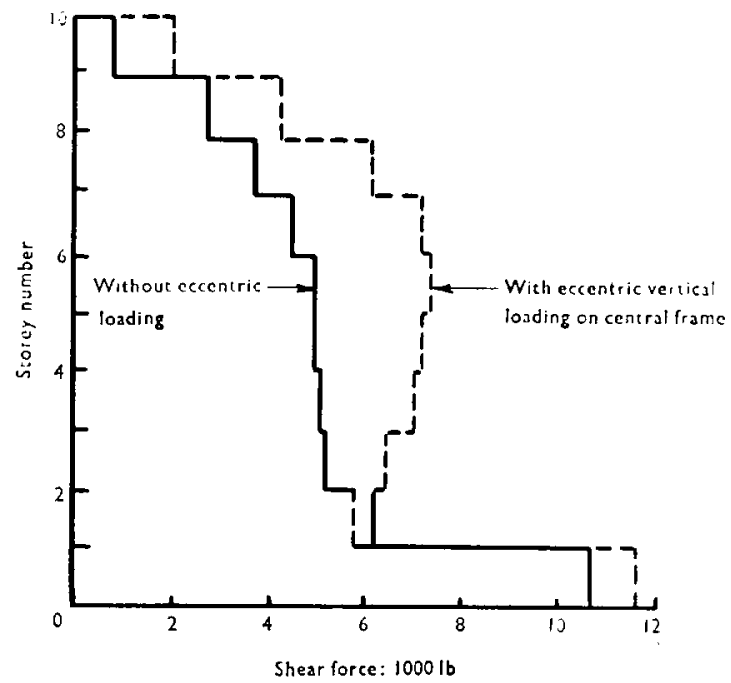

Fig. 25. Shear force transmitted to the central frame of a ten storey, three bay, two shear wall structure

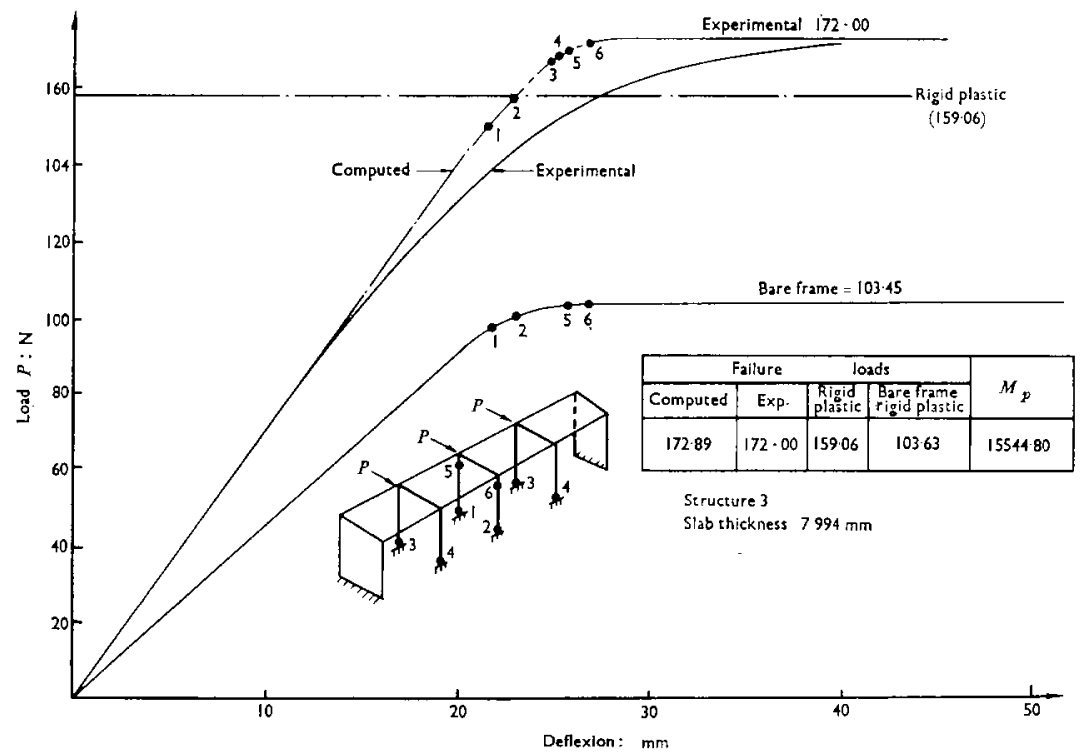

Fig. 26. Load/deflexion diagram 


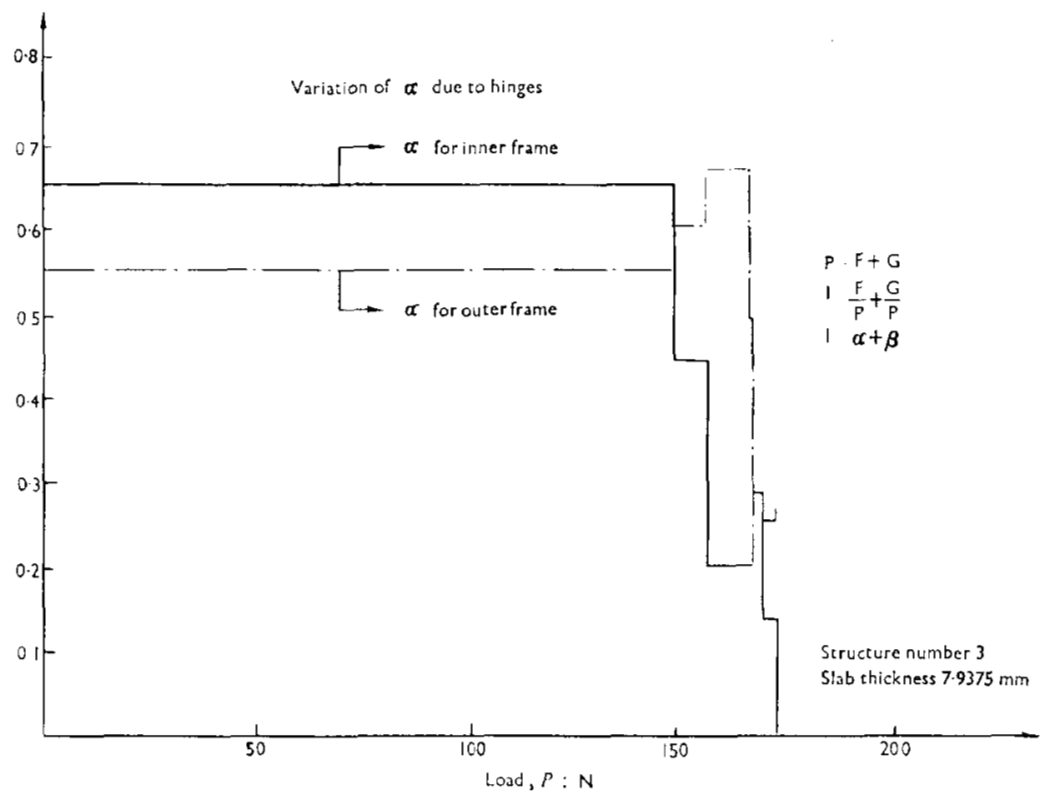

Fig. 27. Variation of $\alpha$ with applied load

i.e.

$$
1=\alpha+\beta
$$

The factor $\beta$ is a measure of the wind load transmitted to the slabs at one of the junctions, which in turn determines the effect of the slab in resisting the applied load, i.e. the stiffness of the cladding.

92. Figure $\mathbf{2 5}$ shows the shear force transmitted to the central frame of a ten storey, three bay, two shear wall structure. The stiffening effect of the cladding is not constant from floor to floor. It is even influenced by the eccentric vertical loading that may be acting on the structure.

93. A true elastic-plastic analysis of a structure reveals further interesting information about the variable nature of the stiffening effect of the cladding. In Fig. 26 the results of such an analysis are compared with those obtained experimentally. The first two plastic hinges develop in the central frame. These weaken the central frame, thus reducing its capacity to sustain its share of the wind load. For this reason more load is transmitted via the slabs to the outer frames and the shear walls. This causes the second set of plastic hinges ( 3 and 4 ) to develop at the outer frames. These too become more flexible and throw the load back to the slabs so that they may transmit it to the shear walls. This phenomenon is substantiated by the Author's results. However, consider the deteriorating values of $\alpha$ for each frame by plotting it as shown in Fig. 27. As the first two hinges develop, the share of the central frame, given by its $\alpha$ value, deteriorates considerably and the loads transmitted through the outer frames increase. Eventually plasticity develops in these outer frames and their share of the load also dwindles. Progressively, therefore, the stiffening effects of the slabs are changing. Among other things, this indicates that, as hinges develop, a proportional increase in the applied external loads does not lead to a similar increase in the loads carried by each individual frame. This fact is not catered for in the plane frame analysis used by Dr Davies. Fig. 26 also shows that the elastic-plastic analysis of a 


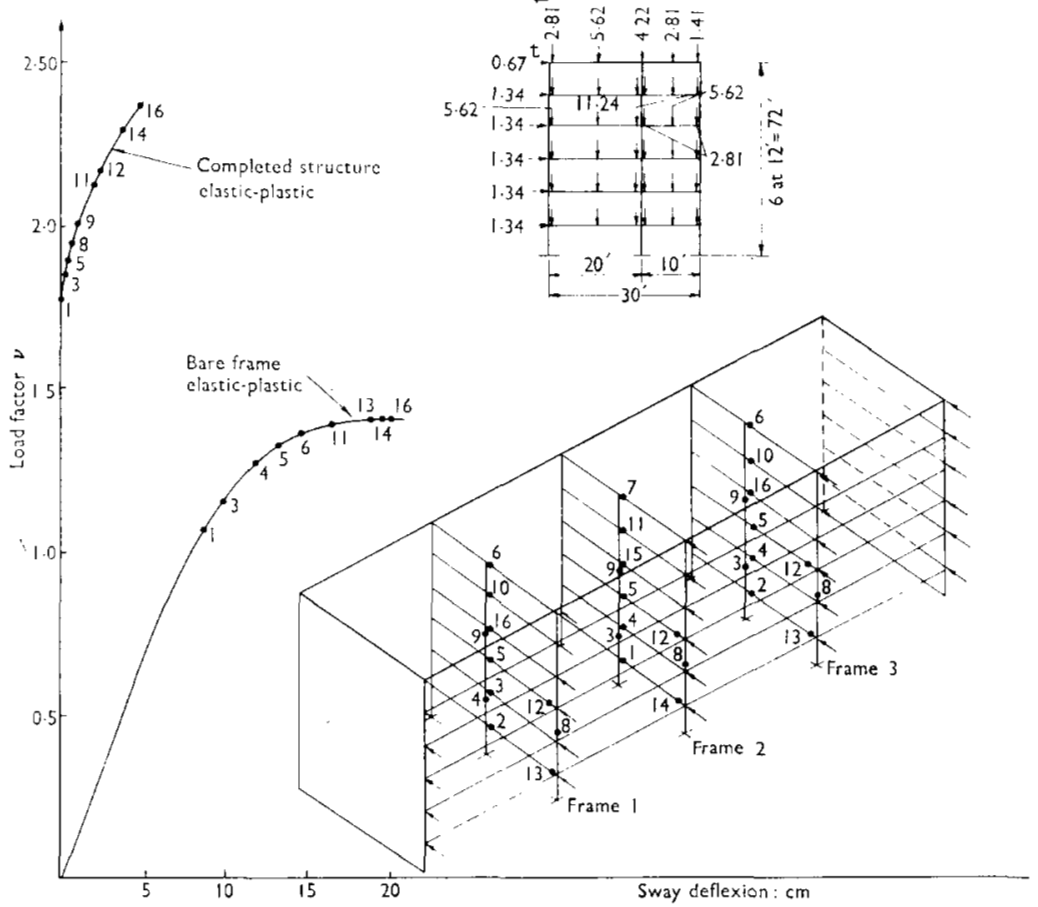

Fig. 28. Six storey, two bay (three frames) structure (composite) under combined loading

bare plane frame is much lower than the actual carrying capacity of the overall structure.

94. An interesting analysis is to obtain the initial value of $\alpha$ for the central frame elastically, then carry out a rigid plastic analysis of the frame subject to its share of the wind load. This analysis underestimates the carrying capacity of the whole structure. This is because the initial value of $\alpha$ exaggerates the role played by this frame throughout the loading procedure up to collapse.

95. A more realistic stucture analysed elastic-plastically at Aston is the six storey, two unequal bay structure with three intermediate frames and two shear walls. The slabs and the shear walls are of reinforced concrete. The structure is shown in Fig. 28 where again the carrying capacity of the whole structure is much higher than that of the bare frame. The structure is subject to wind loads and vertical dead plus super loads. In carrying out the elastic-plastic analysis, the composite effect of the slabs on the plastic hinge moment of the beams was taken into consideration. When a beam is subject to a sagging moment and the slab is in compression, the plastic hinge moment of the beam increases substantially, because of the composite effect. However, hogging moments cause tension in the slab and thus the plastic hinge moment of the beam is considered to be unaffected in this case. Thus each member has two different $M \rho$ values.

96. Also the order of formation of plastic hinges changes from frame to frame and the structure collapses without the development of a mechanism. This, as usual, is due to instability effects. 
Professor M. R. Horne, University of Manchester

An important point about this work is that there has been most successful co-operation with designers and fabricators, resulting in the realization that this is a practical means of design, and this has led to considerable interest from the profession and from the construction industry.

98. The plastic theory is now so generally accepted that many will forget the hard struggle that the academics had in persuading the profession to use plastic theory many years ago. While this difficulty has been overcome by the investigators into stressed skin design, there is a complementary danger, namely that researchers may pay even too much attention to the profession, with the result that they may be nervous of fully exploiting the possibilities of a new approach to design. This could happen here. I think the present stage is satisfactory and that the way in which this work has developed is excellent. It has been brought to a successful conclusion, but there is a way ahead on other aspects, and one should not fear what practising engineers may say about it.

99. Table 1 shows the alternative approaches to the design of single storey frames with some contrasts that arise between orthodox design and stressed skin design. The Author has emphasized that the bare building frame should be capable of carrying the applied loads at a load factor of not less than unity. If this restriction is removed and the complete rationale of design is thought of more from the point of view of the best relative proportions of the structural elements, interesting conclusions follow. Thus, in orthodox construction, cladding units will tend to have a high bending resistance, i.e. they will on the whole have deep corrugations conforming with the general size of the panels. For stressed skin construction, one is more interested in high shear strength and high shear rigidity, and in that case relatively shallow corrugations will be preferred.

100. In orthodox constructions, purlins and sheeting rails are used so as to achieve the greatest economy, this commonly being attained with a fairly wide spacing of the main frames. For stressed skin construction the same sort of proportions can be used if one is prepared to have shear connectors. Alternatively, one may adopt the direct attachment of the cladding to the main members, and in that case there is a disadvantage in having widely spaced frames. Rigid frame economical design is commonly assisted by having deep haunches at the eaves but, with stressed skin action,

Table 1. Alternative approaches to the design of single storey frames

Favoured for orthodox construction

1. Cladding units with high bending resistance, i.e. deep corrugations

2. Purlins and sheeting rails of deep, light section to allow wide spacing of main frames

3. Rigid frame action assisted by deep haunches

4. Low pitch roof for wide spans
Favoured for stressed skin construction

1. Cladding units with high shear strength and stiffness, i.e. shallow corrugations

2. Purlins and sheeting rails of stocky section capable of transmitting shear or shear connectors or direct attachment to main members Some disadvantages in wide spacing of frames

3. Rigid frame action replaced by stressed skin action

Main members behave more as continuous beams

Less advantage in deep haunches

4. Retention of high pitch or use of other shapes 
the stressed skin will itself be primarily responsible for the strength and rigidity of the structure in regard to frame action and the main members will have their main function effectively as continuous beams; in this case there is much less advantage in having deep haunches. From the point of view of orthodox construction, one tends, particularly for wide spacings, to have a low pitched roof. For stressed skin construction it is advantageous to have a relatively high pitch, although, because this may give an undesirable shape, one could consider other shapes, such as those usually associated with shell structures.

101. These differences should be explored because too great an emphasis on what the practising engineer says is practicable, and too great a willingness to be bound by this may force one's structural sense in the wrong direction. Thus, in a rigid frame with cladding capable of sharing the main loading, the stressed skin always fails first, because one is dealing with two rather disparate degrees of rigidity: that of the rigid frame acting as a frame structure and that of the skin acting as a stressed skin. These two forms of structural action have different innate rigidities. In the long term it is not a good idea to try to match the two by taking the two actions in parallel; they should rather be taken in series, using the stressed skin for overall frame rigidity, and using continuous frame construction for the flat grillage behaviour that is needed to provide the out-of-plane bending resistance of the panels of the structure.

\section{Mr H. V. Hill, British Steel Corporation}

I believe the Author started by testing buildings clad with ordinary sine wave corrugated steel sheeting, but the building sponsored by the British Steel Corporation at Salford was a structure clad with a trapezoidal type of profile in 26 gauge steel sheeting. Until now, only the materials which are available have been used. In the light of experience that researchers have had, what kind of quality sheets should be used?

103. A normal galvanized corrugated steel can be made in a variety of profiles, and current thinking prefers the trapezoidal type to the sine wave type, because the more flat material there is in plane with the roof the better the shear performance. Normal galvanized sheets can have a yield stress of about $260 \mathrm{~N} / \mathrm{mm}^{2}$. That kind of steel has a ductility represented by an elongation of about $30 \%$ on a $50 \mathrm{~mm}$ gauge length. By omitting the annealing process in the galvanizing line, a steel can be produced with a yield stress of about $550 \mathrm{~N} / \mathrm{mm}^{2}$, but the ductility is about $3 \%$. Much of this material has been used by the National Coal Board for lagging mines, as it is very strong and very light to handle, using very thin gauges, but it is also used extensively for agricultural buildings. Somewhere between those two-and, I feel, in trapezoidal form-there must be the type of steel that Dr Davies would like to see used.

104. If there is a sufficient demand, the Strip Mill Division can produce a tailormade steel. I think about $350 \mathrm{~N} / \mathrm{mm}^{2}$ would be about the right order of yield stress. By paying a small extra it is now possible to have a certificated guaranteed yield stress of $260-310 \mathrm{~N} / \mathrm{mm}^{2}$.

105. Referring to $\S \S 58$ and 59 , I presume that what is wanted is a reasonable yield stress and a reasonable amount of ductility. What does the Author consider are the right values?

Mr A. Shaw, Archibald Shaw \& Partners

I was fascinated to find that tests had been made on such comparatively large structures. How were the loads applied?

107. With large areas of cladding, if the structure is in the open air is it necessary to wait for a calm day to avoid unwanted wind forces affecting the results?

\section{Dr Davies}

I am pleased that Professor Heyman mentioned the application of stressed skin principles to high-rise buildings. This is an application that my department has not been 
directly concerned with, although the work at the University of Cambridge and the rather different approach being pursued at Cornell University ${ }^{15}$ have been followed with interest.

109. Professor Heyman also raised the question of the effect of changes of geometry on the collapse loads of pitched roof frames. In the Paper I suggested two alternative approaches to the analysis of these composite clad structures in order to evaluate the plastic collapse load. The first is the rigid-plastic method used to derive the failure load of the Manchester shed. This is a simple direct approach and no account of deformations is possible.

110. The second method is the computer analysis which is more comprehensive and follows the response of the structure from first yield to collapse. At each stage the deflexions are known and it is possible to take account of the effect of change of geometry although this introduces the problem of non-linearity. In fact my analysis used a straightforward quasi-linear approach with no second order effects incorporated. It would not have been difficult to take account of various other factors, had this been considered necessary. However, having made a number of assumptions to set up the problem it was not thought to be worthwhile for the type of structures under consideration to take into account any second order effects as this could result in a considerable increase in the consumption of computer time.

111. If this type of action is considered in taller structures, as I think it will be, the analysis can readily be made to take into account frame instability, the effect of strain hardening and any other second order effects considered relevant.

112. I am grateful for Professor Heyman's illustration of the correct way to carry out the rigid-plastic analysis of these three-dimensional structures and I think this clarifies a situation that was previously too obscure. The computer analysis deals with the internal forces in a more precise manner.

113. Professor Bryan raised a number of important questions regarding the design of stressed skin structures using plastic theory.

114. At the present state of the art, no technique for direct design is available and so the design process must proceed by trial and error. A suitable process would appear to proceed along the following lines

(a) approximate design of a single bare frame to a load factor of 1.15 neglecting stressed skin action

(b) approximate design of the cladding panels based on conventional practice, though with shear connectors replacing purlin cleats

(c) analysis of the complete structure for plastic collapse load and for stresses and deflexions at the working loads

$(d)$ adjustment of member sizes and/or sheeting fasteners as a result of $(c)$

(e) re-analysis as necessary.

Step (c) may be considered onerous for a complex structure but a computer program is available which is capable of analysing both the elastic and plastic behaviour at little greater cost than a conventional elastic analysis.

115. Step $(d)$ may require judicious balancing of the strength and stiffness of the frames on one hand and the sheeting panels on the other in order to meet the additional constraint that the sheeting panels must not yield at the working loads. It is here that the designer must take the conscious step mentioned by Professor Bryan in $\$ 80$.

116. In future it will undoubtedly become possible to design such structures directly using a suitable optimization technique. Then the problem of premature yield of the sheeting panels will be readily overcome by the use of a suitable serviceability constraint. ${ }^{16}$

117. In connexion with this difficult question of premature yield at the fasteners in a sheeting panel, I should point out that the analysis is unnecessarily hard on the fasteners. The load deflexion curve of a typical complete sheeting panel, as for example in Figs 20 and 21, starts to become markedly non-linear at an early stage. The actual yield of the sheeting does not take place until considerable non-linear 
deflexion has taken place in the sheeting panels which, in a complete building, would be accompanied by shedding of load to the frames.

118. The prediction of the load at which first yield of the sheeting panels occurs is based on an elastic analysis using the initial stiffness of the panels and this will tend to overestimate the forces in the sheeting panels immediately before yield. It may well be necessary to include a more accurate account of this state of affairs in analyses but for the moment the calculations are certainly conservative.

119. Professor Bryan also asked how the load factor of $1 \cdot 75$ had been chosen for sheeted buildings. There is a well-known rationale that has led to the general adoption of a load factor of 1.75 for conventional rigid frame design using plastic theory. When designing a complete stressed-skin structure, more is known about the structure than when merely designing on a bare frame basis. This being the case, I can think of no valid reason for increasing the load factor beyond that customarily used in a bare frame design.

120. Professor Majid is not completely correct in his suggestion that the analysis was carried out using the computer program described in reference 13 . It would have been possible to analyse the structures using that program but it would have been inefficient. The approach used in reference 13 requires a complete analysis of the structure twice each time a plastic hinge forms and this uses a tremendous amount of computer time as soon as large and complex structures are considered.

121. Some years after the development of this earlier program, I wrote one which is described in reference 8 . This takes advantage of the quasi-linear nature of the response of the structures under consideration making it necessary to solve the complete stiffness equations of the structure only once in order to effect a complete elasticplastic analysis. I was using a modification of this program which $I$ believe uses only a small fraction of the computer time that would have been necessary for the complete elastic-plastic analysis mentioned by Professor Majid.

122. Recently this program has been updated and rewritten in FORTRAN using sparse matrix techniques and incorporating yield in axial tension and compression as well as the formation of plastic hinges. This provides a most efficient elastic-plastic analysis of stressed skin structures costing little more than a single elastic analysis. Although most second order effects are excluded, an allowance for frame instability is readily possible so that there is no difficulty in giving due attention to Professor Heyman's comment in $\S 73$.

123. When considering the question of whether one should describe the contribution of a shear panel by a complete stiffness matrix or by a single elastic constant, one is to some extent torn between the demands of absolute accuracy and the attractions of simplicity. Professor Majid is correct in insisting that there is more to a complete three-dimensional elastic-plastic analysis than is contained in the Paper. However, I would agree for the single coupling term representing the flexibility of a complete panel for this particular application on the basis that it does give a very good representation of what happens in practice and therefore I do not see any real advantage in adding various extra complications into the analysis. The problems appear to me to be practical rather than analytical.

124. Professor Majid pointed out that the bending stiffness of the shear panel should not be neglected. In fact, it is not completely neglected. The term $c$ is strictly speaking just a shear flexibility, but it includes an approximate allowance for the bending flexibility of the panel. It does not treat the bending flexibility exactly, but for typical panels of roof sheeting this is by no means dominant. An approximate allowance for the bending flexibility has been adequate for the structures considered and this problem has been studied in detail.

125. In this connexion the derivation of the strengths and stiffnesses of complete cladding panels is no longer empirical but has a sound theoretical basis so that they can be calculated without the need for experimental determination.

126. Professor Majid implied in $\S 93$ that the analysis did not take into account the 
full redistribution of external forces between the frames and the cladding panels as plasticity caused a change of relative stiffness. This is so for the manual rigid plastic analysis but this redistribution is faithfully accounted for in the full computer analysis.

127. I am reluctant to be drawn into a discussion of the application of my work to three-dimensional elastic-plastic analyses of steel/concrete composite structures as it is not intended to apply to this more difficult problem. However, I should be interested to know how Professor Majid dealt with the practicalities of incorporating the in-plane shear failure of reinforced concrete slabs in his analysis because I imagine this must happen before the complete structures can fail by the (partial) mechanisms he describes.

128. Professor Horne's contribution raised some fundamental questions regarding the philosophy behind the whole approach to the stressed skin design of steel-framed structures. His final conclusion in $\S 101$ is very much in agreement with experience at the University of Salford in promoting the practical utilization of stressed skin design. Despite the fact that the Paper and the vast majority of Professor Bryan's pioneer investigations in the field have been concerned with the effect of cladding in enhancing the strength and stiffness of rigid-jointed frames, the major practical applications of the stressed skin principles have been in providing the entire stiffness of pin-jointed frames. Thus the CLASP and SEAC building systems and the new Covent Garden fruit and vegetable market all use stressed skin action to provide the primary stability of pin-jointed structures.

129. I am grateful to Professor Horne for his lucid exposition of the problem of the conflicting demands of orthodox and stressed skin construction. One recent approach used at the University of Salford can be seen as the logical conclusion of Professor Horne's suggestions. Thus, given a pitched roof structure with sufficient pitch and with a little support along the eaves line (e.g. from the side sheeting), the roof sheeting, together with the apex and eaves purlins, can span a considerable distance without any help from the frames. Pursuing this line of thought and adjusting slightly the arrangement of the sheeting and the purlins, or rather the members that replace them, gives the folded plate structure shown in Fig. 29 . Longitudinal members occur at the fold lines only and all the load is carried by folded plate action with no transverse frames other than those at the gables. Such structures have been built in the USA using all welded construction. There seems to be no reason why spans of up to $30 \mathrm{~m}$ should not be possible using conventional sheeting fasteners and without the expense of site welding.

130. Research into light gauge folded plate construction and also into related light gauge shell type structures is continuing at the University of Salford as part of

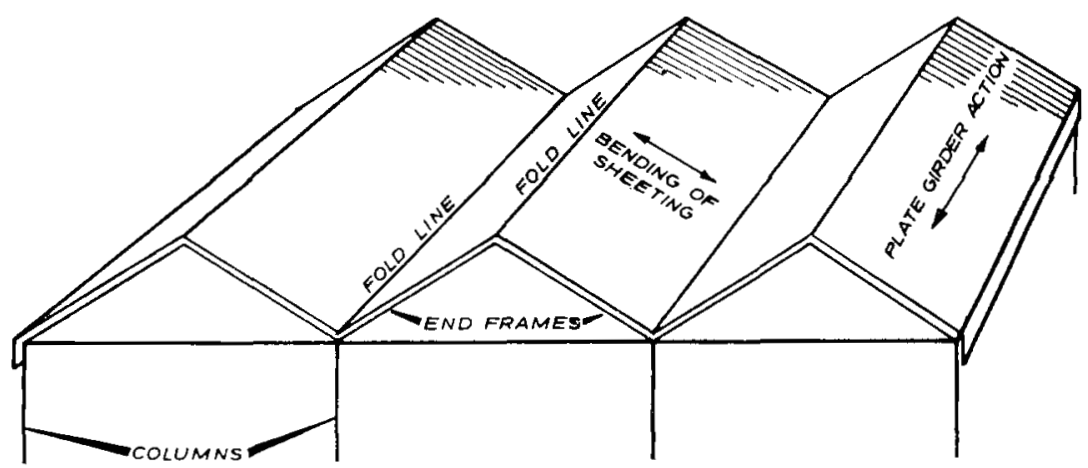

Fig. 29. Typical light gauge steel folded plate structure 
a comprehensive investigation into the various aspects of the stressed skin construction of steel buildings.

131. Mr Hill asked how the manufacturers of corrugated steel sheeting and decking can help stressed skin designers by manufacturing steel with the most suitable properties. There are three variables over which the manufacturer has some control, namely the size of sheet, the profile and the quality of the steel.

132. The size of sheet can be important and clearly the larger the area of each individual sheet the better, but there is probably little room for manoeuvre here because there are practical considerations that restrict the size of the sheets.

133. The profile is also important and Mr Hill outlined one of the reasons why trapezoidal corrugations may be preferred. However, as Professor Horne pointed out, the sheeting profile is usually governed by considerations of bending resistance so that the stressed skin designer may not have much control here.

134. The steel quality affects the strength of the shear diaphragm but not its stiffness. By increasing the yield strength of the sheeting one improves its carrying capacity without attracting any more load, and this must be desirable.

135. However, as Mr Hill explained, extra strength is only attainable at a cost in terms of ductility and it is necessary to compromise between two conflicting requirements. The crucial factor in this respect is the performance of the sheeting at the fasteners where strength is not necessarily directly related to the yield strength of the steel sheeting and ductility is not necessarily a simple function of the percentage elongation at fracture. In other words, it is not possible to give a simple answer to the question raised in $\S 105$; it would be necessary to carry out a series of tests on fasteners, varying the steel quality, steel thickness and the fastener type, before one could be sure of exactly what is required.

136. Mr Shaw's final question really requires a further paper which I feel should be presented by Professor Bryan who was responsible for all three of the large scale tests referred to in the Paper. There were three tests and all were different. For the first test, at Manchester University, point loads were applied to the apexes of pitched roof frames by dead load and levers. For the second test, at Barton Airport, the side load was applied through hydraulic jacks reacting against $A$ frames. Vertical load was also applied to the flat roof by distributing pre-weighed bags of sand over the area of the roof. For the third test, at Salford University, it was required to simulate a uniformly distributed load on a pitched roof structure. A complex lever system connected to a series of jacks provided the vertical load. Side load was also applied hydraulically at eaves level through a cable system.

137. Although the tests at Barton were done in the open air there was no side cladding and typical Manchester area weather conditions ensured that rain was a more significant problem than wind.

\section{References}

12. Oppenheim I. J. Control of lateral deflexion in planar frames using structural partitions. Proc. Instn Civ. Engrs, Part 2, 1973, 55, June, 435-445.

13. Jennings A. and MAJID K. I. An elastic-plastic analysis, by computer, for framed structures loaded up to collapse. Struct. Engr, 1965, 43, No. 12, 407412.

14. MAJID K. I. Elastic plastic structural analysis. PhD thesis, University of Manchester, 1963.

15. SEXSMITH R. G. et al. Interaction of diaphragms and multi-storey building frames. Progress Reports I and II. Department of Structural Engineering, Cornell University, 1971.

16. Davies J. M. A new formulation of the plastic design problem for plane frames. Int. J. Numer. Meth. Engng, 1972, 5, No. 2, Nov./Dec., 185-192. 